\title{
Guest Editorial Special Section on Electric Vehicle Technology
}

I AM VERY GLAD to be able to present a Special Section on Electric Vehicle Technology in this issue of our TRANSACTIONS. On the eve of going to press with this special section, I was confronted by the following data. As recently as 1950, there were only 53 million motor vehicles registered in the world, and their exhaust emissions could still be tolerated because of their relatively modest effects. In 1992, our planet had well over half a billion cars and trucks! By the year 2000, their number will exceed one billion! If they were all to be powered by gasoline and diesel oil, our world could not stand it. Therefore, one of the most pressing demands of our time is an alternative clean, efficient, intelligent, and environmentally friendly urban transportation system. Electric vehicles offer a solution for improving air quality, reducing reliance on fossil fuels, and they are energy efficient. Furthermore, electric vehicles will be more intelligent to improve traffic safety and road utilization. In this special section, there are ten papers authored by researchers in academia and industry. These papers address the state of the art as well as some of the key issues and key technology of electric vehicles. The first paper, by Chan and Chau, provides an overview of current electric vehicle technology and the challenges ahead. The second paper, by Shimizu, Harada, Bland, Kawakami, and Chan, describes a unique ECO Vehicle Project in Japan with an in-wheel motor drive system, a hollow load floor which accommodates the batteries, and a new battery management system. The third paper, by Ehsani, Rahman, and Toliyat, addresses the system design philosophies of electric and hybrid vehicle propulsion systems. The dynamics are studied in an attempt to find an optimal torque-speed profile for the

Publisher Item Identifier S 0278-0046(97)00066-X. electric propulsion. The fourth paper, by Terashima, Ashikaga, Mizuno, Natori, Fujiwara, and Yada, describes unique inwheel motors for a high-performance experimental electric vehicle. The fifth paper, by Profumo, Zhang, and Tenconi, describes alternative axial flux induction or synchronous inwheel motors for electric vehicles. The sixth paper, by Rahman and Qin, presents the design, analysis, and PWM vector control of a hybrid permanent magnet hysteresis synchronous motor for electric vehicle application. The seventh paper, by Mutoh, Kaneko, Miyazaki, Masaki, and Obara, describes a torque controller which suits electric vehicle operating conditions. The eighth paper, by Kawamura, Hoshi, Kim, Yokoyama, and Kume, proposes an anti-directional-twin-rotary motor drive as a new power train for electric vehicles. The ninth paper, by Lai, presents resonant snubber-based soft-switching inverters for electric propulsion drives, which have superior performance in efficiency improvement, EMI reduction, and $d v / d t$ reduction. The last paper, by Kim and Ha, deals with the design of interface circuits with electrical battery models. On the whole, the above ten papers address important technology for the next century. They deal with the key components in electric vehicle development, namely system design philosophy, various options of electric motor drives and energy management. These are challenges for our profession. The 21 st century will be the environmental century, and electric vehicles will be the major means of urban transportation.

C. C. CHAN, Guest Editor

Dept. Electrical \& Electronic Engineering University of Hong Kong Hong Kong 


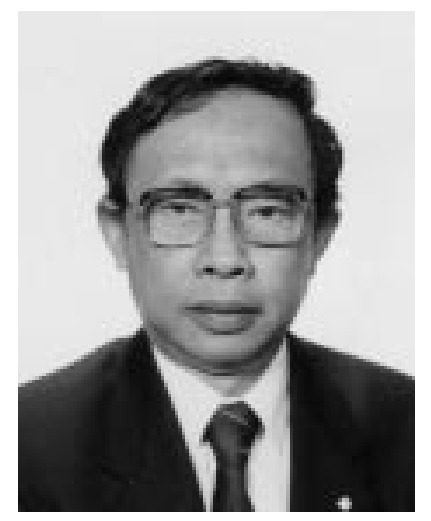

C. C. Chan (M'77-SM'77-F'92) received the B.Sc. degree from China University of Mining and Technology, the M.Sc. degree from Tsing Hua University, and the Ph.D. degree from the University of Hong Kong, all in electrical engineering, in 1953, 1957, and 1981, respectively, and was awarded the Honorary D.Sc. degree from the University of Odessa in 1993 for his prominent contributions in the areas of modern electric drives and electric vehicles.

He started his professional electrical engineering career in 1959. He has worked 11 years in industry and 24 years in academic institutions. He is currently the Endowed Honda Professor and Head of the Department of Electrical and Electronic Engineering, University of Hong Kong. He is also the Director of the International Research Center for Electric Vehicles at the University of Hong Kong, which he founded in 1986. He is the co-founder of the World Electric Vehicle Association. He was a Visiting Professor at several well-known universities, including the University of California, Berkeley, and the Massachusetts Institute of Technology, Cambridge. He holds more than 20 posts in international committees, and serves as a consultant to several organizations in Hong Kong and the U. S. In 1990, he hosted the 10th International Electric Vehicle Symposium in Hong Kong. He is currently advising electric vehicle development programs for several leading companies worldwide. He has authored and co-authored 4 books and more than 100 technical papers, and holds seven patents. He was elected an IEEE Fellow in 1992 for his contributions to the advancement of electric drives and electric vehicles and was awarded the IEEE-IECON Best Paper Award and the Alcan Technical Excellence Award for his contributions.

Prof. Chan is also a Fellow of the IEE and HKIE, Chairman of an IEEE Technical Committee, and is listed in International Leaders of Achievement, Men of Achievement, and Who's Who in Australasia and the Far East. 